\title{
Predisposing Factors to Lateral Ankle Injury in Male Comrades Marathon Runners
}

\begin{abstract}
:
Introduction: More than two million people experience ankle ligament trauma each year in the United States. Half of these are severe ligament sprains, however very little is known about the factors that predispose individuals to these injuries. The purpose of this study, (which was conducted as an undergraduate research project), was to find a correlation between the characteristics of height, weight and limb dominance and lateral ankle ligament injuries.

Method: A retrospective study was conducted on 114 ultra distance runners who participated in the 2006 Comrades Marathon. During race registration, the runners' height and weight were measured after answering a questionnaire regarding their training.

Results: 114 runners responded to the questionnaire. From this cohort, $38(33.3 \%)$ had sustained previous lateral ankle injuries. Of these 38 injuries, $47.4 \%$ of the injuries occurred on the runner's dominant limb and $36.8 \%$ occurred on the non-dominant side. $15.8 \%$ of the runners sustained previous ankle injuries to both ankles. There was a low negative correlation coefficient of 0.24 with regards to weight as a risk factor. This indicated that the power of the correlation was $5.93 \%$. The study demonstrates that there is no correlation between an increase in weight and an increase in the incidence of ankle injury. The correlation coefficient indicated a low correlation between an increase in height and the incidence of ankle injury. However, the power of the correlation at $18.37 \%$ makes inaccurate any attempt to predict the height at which a runner would be at most risk for lateral ankle injury.

Conclusion: Height and weight are not risk factors predisposing subjects to lateral ankle injury. In addition, the study illustrated that there was no effect of limb dominance on the incidence of lateral ankle injury.
\end{abstract}

KEYWORDS: ANKLE SPRAIN, HEIGHT, WEIGHT, LIMB DOMINANCE.

\section{INTRODUCTION}

Recent research has suggested that runners who exhibit relatively large and rapid impact forces while running are at an increased risk of developing an overuse injury of the lower extremity (Hreljac, 2004). Modifications in training programmes could facilitate return to running with a shortened rehabilitation period. Should the runner be assessed to have the predisposing characteristics to lateral ankle injury, it would be advantageous to advise runners on the potential for injury before commencing a running programme, This could result in injury prevention or early treatment intervention of injuries. Among the modifiable risk factor studies, a training distance of less than $40 \mathrm{~km}$ a week is a strong protective factor for lower extremity injuries (van Middelkoop et al, 2007). Hence the ankle is susceptible to injury in long distance marathon runners.
The ankle complex plays a crucial role in human locomotion (Gage et al, 1995) and this may be one of the reasons for the high number of injuries to the ankle. The anatomy of the ankle ligaments accounts for the bias towards lateral ankle injury compared to medial ankle injuries. Inversion injuries are far more common than eversion injuries due to the relative weakness of the lateral ligaments compared to the medial ligaments (Brukner and Khan, 2005).

Much of the literature is based on the assumption that risk factors are present. These risk factors are said to predispose one to sustaining an ankle injury (Beynnon et al, 2001). Some of the hypothesized intrinsic risk factors include; sex, previous sprain, anatomical foot type, foot size, muscle strength, joint laxity, height, weight, and limb dominance (Beynnon et al, 2002).

Three predisposing risk factors for ankle sprain were chosen for this study, namely height, weight, and limb dominance. These characteristics can be measured and recorded accurately and with ease. As this is a retrospective study, any previous ankle injury would not confound current measurements of these characteristics. Previous studies incorporating these factors have shown varying results.

\subsection{Comrades Marathon}

The Comrades Marathon is the worlds' oldest and largest ultra marathon. It is

\section{Correspondence to:}

Nirmala Naidoo

Department of Physiotherapy

University of KwaZulu-Natal

Private Bag X54001

Durban 4000

Tel: (031) 260-7817

Fax: (031) 260-8106

E-mail: naidooni@ukzn.ac.za 
run over a distance of approximately 90 kilometres (55,9 miles) between Durban and Pietermaritzburg in KwaZulu Natal, South Africa. The direction of the race alternates each year between the up run starting from Durban and the down run starting from Pietermaritzburg.

All entrants must qualify by completing an officially recognized race according to stipulated cut off times for the period from June (after the run) to May (of the next year, before the race). Athletes currently have 12 hours to complete the course. This was extended from 11 hours in 2003. There are a number of cut-off points along the routes which runners must reach by a prescribed time or be forced to retire from the race. Medals are awarded to all runners completing the course in less than 12 hours (Comrades Marathon Association, 2008).

\subsection{Principles of Levers}

Ankle mobility may be correlated to a systems of levers (Figure 1). A lever is any rigid bar that turns about a fulcrum when force is applied to it. In the process of turning, it overcomes resistance. The lever has three important points: the point around which it turns, the point where the force is applied and the point at which the resistance to its movement is applied. Since there are three points, there are three possible arrangements of these points. Figure 1 illustrates these three alternatives: number 1 is a first class lever where the fulcrum lies between the force and the resistance point; number 2 is a second class lever where the resistance point lies between the fulcrum and the force point; number 3 is a third class lever where the force point lies between the fulcrum and the resistance point. First class levers will be examined specifically in this study.

The portion of the lever between the fulcrum and the force point is called the force arm. Similarly, the portion between the fulcrum and the resistance point is known as the resistance arm. A lever will balance when the product of the force $(\mathrm{F})$ and the force arm (FA) equals the product of the resistance $(\mathrm{R})$ and the resistance arm (RA). Giving us the following equation: $F^{*} F A=R * R A$.
Figure 1: Lever classes.

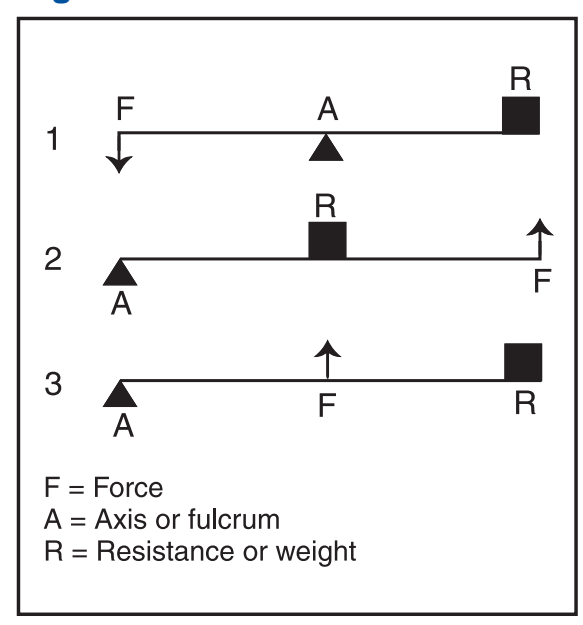

In the context of this study, the resistance arm is the distance from the sole of the foot to the ankle joint, the ankle joint is the fulcrum, and the force arm is the distance from the ankle joint to the top of the head.

When the ankle is in a position of potential injury where the resistance arm is prevented from moving, an increase in FA (height) would increase the torque force at the fulcrum (ankle joint), and decrease the effort at which this force is produced. The same can be said by increasing $\mathrm{F}$ (weight). The torque force at the ankle joint will increase and without the ability of the resistance arm to move, the structures around the ankle joint will bear the strain.

The principle of levers leads us to believe that the characteristics of height and weight are indeed risk factors, predisposing athletes to ankle injuries. The study by Giza et al (2003) identified the most common position of the foot and ankle at the time of injury in soccer players, was weight-bearing in the position of inversion at the subtalar joint. In this position, an increase in either weight or height will subsequently increase the lever arm and proportionally increase the torque force on the ligaments and muscles at the ankle complex, which acts as the fulcrum. The lateral aspect of the ankle capsule is enhanced by the anterior and posterior talofibular ligaments and by the calcaneofibular ligament. Of these structures, the anterior talofibular and calcaneofibular ligament are considered the most important stabilizing structures (Leardini et al, 2000).

\subsection{Limb dominance}

Current literature concerning the parameters for determining limb dominance are vague and contradictory, however, there seems to be three common considerations;

- The relative preference for one limb in the execution of a unilateral task (Annett, 1970; Peters, 1998).

- The greater skillfulness of one leg in the performance of a task (Gabbard \& Hart, 1996; Peters, 1998).

- The greater strength and/or endurance of one limb (Bowman \& Katz, 1984; Chau et al., 1997; Dias, Bhowal, Wildin, \& Thompson, 2001).

When examining limb dominance as a risk factor, the general consensus is that most athletes would place more stress and strain on their dominant limb, and when off balance, may tend to use their dominant limb to maintain balance and this may lead to injury of that ankle (Murphy et al, 2003).

It was accepted that all runners participating in this event would have the knowledge and experience to judge which was their dominant limb. A positive response for a previous ankle injury in the current study included all grades of sprains. The injury if not diagnosed by a medical professional, would either have required the runner to decrease or stop training for a period of time.

In the light of previous studies on this topic having such varied results, finding a significant relationship between the variables of height, weight and limb dominance and previous lateral ankle injuries would clarify our current knowledge on the subject.

\section{LITERATURE REVIEW}

Databases consulted included Pubmed, CINAHL, Medline and PEDro. Previous research on risk factors for lateral ankle injuries revealed a paucity of studies relating ankle injuries to long distance runners. Many studies have included soccer, basketball and lacrosse players as well as military recruits. These activities investigated place a great deal of emphasis on agility and a quick change in direction, in comparison to running that is done at a relatively steady pace and usually in a straight line. On the other end of the spectrum, few athletes 
surpass the amount of time put into training by ultra marathon runners.

There is much in the literature to support lower limb injuries related to running. Van Gent et al (2007) conclude that the majority of injuries are related to the knee. They state that running the year through without a break would deem athletes more susceptible to lower limb injury. However, few studies have investigated ankle injuries specifically in long distance runners.

\subsection{Height and Weight}

In 1991 Milgrom et al conducted a prospective study on 390 Israeli military recruits during basic training, in an effort to identify risk factors for ankle injuries. Of the 390 subjects, $18 \%$ (70 subjects) experienced lateral ankle sprains. It was not specified what types of training subjects did during basic training. The results of this study concluded that the recruits who were taller and heavier than their fellow recruits sustained more lateral ankle sprains.

In 1999, Watson investigated ankle sprains in athletes who participated in hurling and Gaelic football. The small sample population of eight athletes in the prospective study was conducted over a four year period. Subjects were monitored during practice and during games and events. The researcher found that subjects who sustained ankle sprains had greater height than fellow subjects.

McKay et al (2001) conducted a study of recreational basketball players with the intent to establish risk factors for ankle injuries. A sample of 400 Australian basketball players was included in the study, 37 of which sustained ankle injuries. The results indicate that there was no significant difference detected between the height and weight for the injured group and the non-injured group. Hence it was ascertained that these characteristics are not significantly related to the occurrence of ankle injury. Beynnon et al (2001) conducted a study of 118 Division 1 collegiate athletes who participated in soccer, lacrosse, or field hockey. Of the 118 subjects, twenty sustained ankle injuries. The differences in height and weight between injured and non-injured subjects was statisti- cally insignificant, thus Beynnon et al (2001) found the characteristics of height and weight not to be risk factors for lateral ankle injuries.

Tyler et al (2005) conducted a study of one hundred fifty-two athletes from four football teams. Two teams were observed for three seasons, and two teams were observed for one season with twenty-four ankle sprains occurring in this period. After statistical analysis, it was determined that body mass index (BMI) was a risk factor for ankle injuries. These results implicate the characteristic weight, as subjects that were heavier would have a higher BMI $(>25 \mathrm{~kg} / \mathrm{m} 2)$ and were at greater risk of injury. This study showed that on average, injured athletes were $1.53 \mathrm{~cm}$ taller than non-injured subjects, and on average, injured subjects weighed $1.32 \mathrm{~kg}$ 's more than non-injured subjects. As previous studies have shown, this is statistically insignificant. The current study also determined a correlation between the variables and the incidence of lateral ankle injury. The correlation co-efficient values calculated support the above averages in showing little or no correlation. In summation, as research has progressed through the years, it is becoming apparent that independently height and weight are not risk factors for ankle injury. The study of Tyler et al (2005) has however demonstrated that in other forms, the characteristics of height and weight may yet be considered as risk factors.

\subsection{Limb dominance}

Literature on limb or leg dominance as a risk factor for ankle injury is fairly divided. The inclination is towards injury of the dominant limb, in accordance with the thought that greater demand is placed on that side (Murphy et al, 2003).

Ekstrand and Gillquist (1983) found that among male soccer players, injuries sustained to the dominant side were significantly higher than that of the non-dominant side. The study included 180 subjects from a senior division soccer league in Sweden. Results showed that $92 \%$ of the 44 ankle injuries took place on the dominant ankle. On the contrary, when Surve et al (1994) conducted a study on soccer players a few years later they found that there was no relationship between ankle injuries occurring on either the dominant or non-dominant leg.

In a more recent study done by Beynnon et al (2001), results corresponded with Surve et al (1994), in that they found no difference in the incident rate of ankle injury between dominant and non-dominant limbs. In the study of men and women who participated in a variety of sports, $77 \%$ of the ankle injuries occurred on the dominant side. The same was not found for the male group, where $57 \%$ of the injuries occurred on the dominant side, showing a more even likelihood of injury. These varied results allowed the authors to disregard limb dominance as a predisposing factor for lateral ankle injuries. On reviewing the literature, it may be considered that there has been a change of thought in terms of limb dominance, as more studies have been done, although inconclusive. This study had a group of 38 subjects with previous lateral ankle injuries; $47.4 \%$ of the injuries occurred on the dominant limb and $36.8 \%$ occurred on the non-dominant limb. These figures coincide with the most recent study of Beynnon et al (2002), and support the idea that limb dominance has no effect on which limb is injured.

\section{METHODOLOGY}

\subsection{Subjects}

The annual Comrades Marathon Expo is held in Durban, KwaZulu-Natal. This provides a venue for registration of runners and for sponsors and service providers including Physiotherapy. Thousands of runners attend the Comrades Expo to register for the race. The Expo is run over three days before the Comrades Marathon, and gives the runners an opportunity to consult with service providers, sponsors and meet other runners. Among these are services provided by physiotherapists including strapping, injury advice and a massage facility. Subjects were randomly selected from those runners queuing to receive a complementary consultation and massage by Physiotherapists. 


\subsection{Study design}

This is a retrospective study as subjects were questioned about previous ankle injury, training preparation and leg dominance. This type of study can be carried out in a short space of time, however only prospective studies can control multiple variables that are difficult to accurately measure and evaluate after an injury has occurred. An example would be joint-laxity, which may increase after injury, so base line measurements are taken prior to the staging period. This allows the subjects to be monitored during a given period of time to investigate the affect of the characteristic on the prevalence of injury. This study investigated weight, height and limb dominance, which would not drastically change after injury, thus allowing the study to be retrospective in nature.

\subsection{Instrumentation}

\subsubsection{Tape measure}

A non-elastic plastic tape measure with $\mathrm{cm} / \mathrm{mm}$ demarcations was used. It was attached to a steel girder by means of tape.

\subsubsection{Digital scale}

A digital scale, correct to one decimal place, was used to measure subjects' weight. The scale was tested for reliability by weighing and re-weighing the researcher's body weight three times. The reliability was high, as the weight recorded was equal for all three measurements. The validity was tested against a gold standard of gym weights of 10,15 and $20 \mathrm{~kg}$ denominations. Each weight was measured three times, and recorded. The results showed 100\% validity as each measurement showed the exact denomination of the weight used. This was done only one time prior to the start of the data collection.

\subsubsection{Questionnaire}

The questionnaire contained both closed and open-ended questions. Examples of questions include training regimen, training surfaces, mileage and hours of training for the 2006 Comrades marathon, cross-training, anatomical disposition of feet (flat feet, high arched or normal arched feet), and previous ankle injuries. The questionnaire was piloted using students who were runners. These questions were designed to establish whether any ankle injuries were associated with the three risk factors in this study, and to establish any other variables.

\subsection{Procedure}

Ethical clearance to conduct the study was obtained from the University of KwaZulu-Natal Faculty of Health Sciences Ethical committee. Subjects were randomly selected from those runners queuing to receive a complimentary massage at the Physiotherapy stand set up at the Comrades Marathon Expo Centre, Durban. Subjects received informed consent and submitted signed consent before completing the questionnaire.

Subjects were individually escorted from the queue at the Physiotherapy massage station to an area set up specifically to conduct the study. A brief introduction was given to the subject about the study, after which they were asked to sign a consent form. Once the consent form was signed, the questions from the questionnaire were recited to the subject and the answers were entered onto the questionnaire by the researcher. To ascertain which was the subject's dominant limb, runners were asked which limb they believed was their strongest limb, if they were unsure, they were asked which foot was used in sports involving kicking. This was deemed to be a fair assessment as the subjects are ultra marathon runners who are knowledgeable about running and injuries associated with running. For weight measurements, subjects were requested to remove their shoes and all heavy items on their person. Subjects then stood on the scale, while the researcher took the reading. Subjects were then requested to step off the scale and stand erect with their back against the steel girder to which the tape measure was attached. A height measurement was taken at the level of the highest point of the subjects' head using a rigid board that was held perpendicular to the tape measure. Once done, the next subject was selected from the queue.

\subsection{Data Analysis}

Questionnaires were divided into those with previous ankle injuries, and those without. Responses were added and averaged and then compared with each other. Height and weight measurements were totaled, averaged and plotted on scattergrams, as well as analyzed to calculate their respective correlation coefficients and percentage variance explained. Results on limb dominance were analyzed to calculate the percentage of previous ankle injuries that occurred on the subjects' dominant limb, non-dominant limb, or on both limbs.

\section{RESULTS}

114 runners participated in the study. 114 questionnaires were completed and collated using Microsoft Excel. Table 1 represents the majority of the results gained from the questionnaires. Graph 1 represents the incidence of lateral ankle injury on the dominant, non- dominant and on both limbs in percentage. Graph 2 and 3 are graphical representations of the relationship between weight and the incidence of injury, and height and the incidence of injury. Tables 2 and 3 contain values calculated from graph 2 and 3 respectively.

Statistics gathered from the questionnaire show that of our 114 subjects, the average mileage done in training for the 2006 Comrades marathon was $1155 \mathrm{~km}$, which indicates that our subjects spent a lot of time on their feet, increasing their chance of injury. The average number of Comrades marathon completed by our subjects was 4.5 , which illustrates that these subjects have been running for a good number of years, and are presumably well experienced in the sport, and knowledgably about their foot type and about running injuries.

\section{DISCUSSION}

\subsection{Limb dominance}

The majority of those runners who had previous ankle injury reported injury in the dominant limb $(47,4 \%)$ and $36,8 \%$ of the injuries were sustained on the non-dominant limb. These results concur with the study Beynnon et al (2001) on college athletes, where no difference was found in the incidence of injury on 
Table 1: Referencing subjects and training parameters.

\begin{tabular}{|l|l|l|l|}
\hline & & Uninjured & Injured \\
\hline Subjects & & 76 & 38 \\
\hline Age & Age [S.D.] & $38[10.75]$ & $40[8.95]$ \\
\hline Height & Height (cm) [S.D.] & $171.82[6.16]$ & $173.35[9.87]$ \\
\hline Weight & Weight (kg) [S.D.] & $71.33[9.99]$ & $72.65[11.47]$ \\
\hline Foot Type (\%) & Normal & 67.1 & 73.7 \\
& Flat foot & 23.7 & 18.4 \\
& High Arched & 9.2 & 7.9 \\
\hline Cross Training (\%) & Yes & 44.7 & 39.5 \\
& No & 55.3 & 60.5 \\
\hline Average Comrades completed & & 4 & 5 \\
\hline Novice runners (\%) & & $18(24)$ & $4(11)$ \\
\hline Projected finishing time (hours) & & 8.83 & 6 \\
\hline Approx. training mileage (km) & & 1165 & 1144 \\
\hline Best 10km time (minutes) & & 44.75 & 42.83 \\
\hline
\end{tabular}

Graph 1: Percentage of lateral ankle injury occurrence

either limb. Their results show that in male subjects, $57 \%$ of the ankle injuries occurred on the dominant ankle; however the group of injured subjects was small, with only seven subjects. The results from the current study may be explained by the nature of road running as a sport, which compared to other sports such as rugby and football, does not require any 'side stepping' or much quick movement. This may have been observed in the study conducted by Ekstrand and Gillquist (1983) on soccer injuries. Their results contradict the current results in that of the 39 players who sustained ankle injuries, 36 (92\%) occurred on their dominant limb. The increased incidence of injury to the dominant limb may be as a result of heavier weight-bearing on that limb thereby making it more susceptible to injury. Results are however still divided.

Additionally, the estimated working range of active muscle fibres in forcelength relationship could shift more to a shorter length phase in running (Ishikawa, 2007). This could further contribute to overuse and increased incidence of injury.

\subsection{Weight}

The results concerning the relationship between the subjects' weight and the incidence of injury show a weak nega-

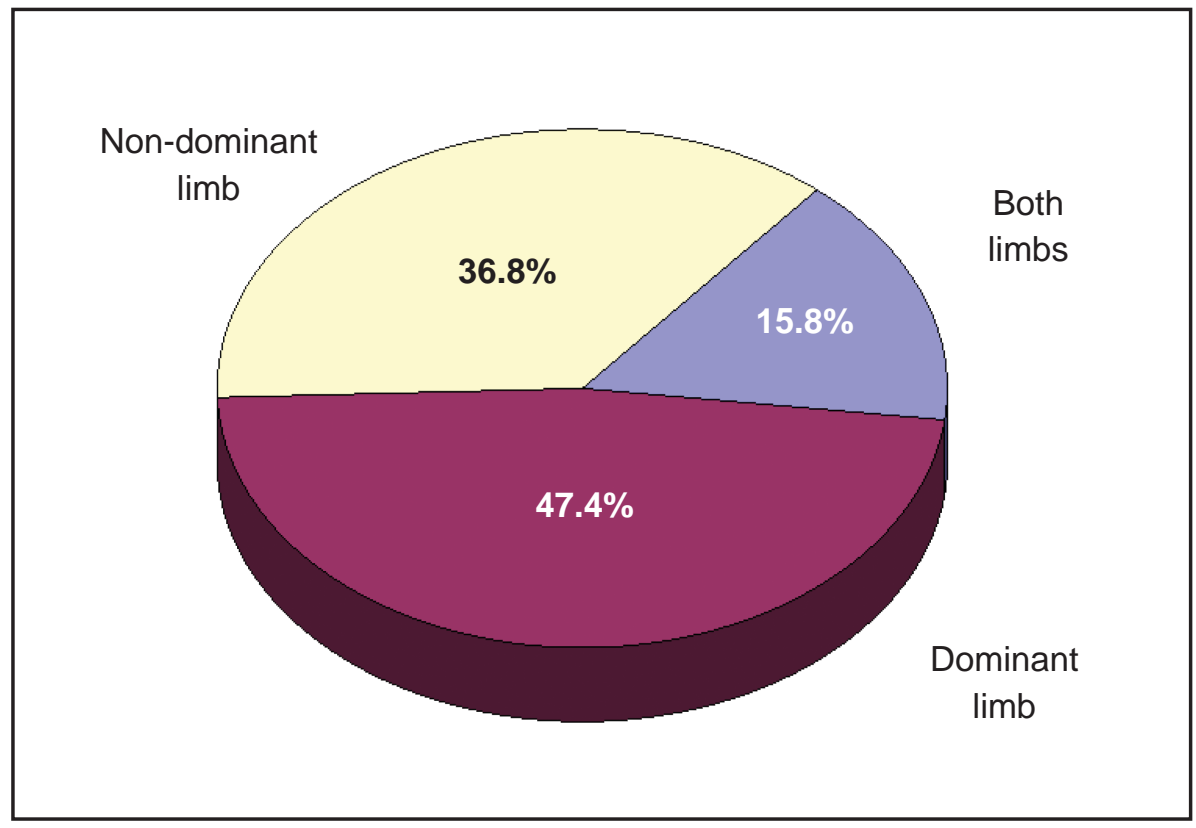

tive correlation coefficient of 0.24 , as the incidence of injury actually decreases as subjects weight increased. This low figure indicates that there is no relationship between the two variables. The average weight for uninjured subjects was $71.33 \mathrm{~kg}$ 's, while the average for injured subjects was $72.65 \mathrm{~kg}$ 's. This would indicate that, on average, injured subjects were $1.32 \mathrm{~kg}$ 's heavier than non-injured subjects. This is not significant, and illustrates that weight is not a risk factor for lateral ankle injuries in this cohort. These results agree with those of both Beynnon et al (2001) and Sitler et al (1994) whose studies of college athletes and basketball players respectively found that weight was not an independent risk factor for lateral ankle injuries. Li et al (1999) stated that the energetic cost of running is correlated with the weight that the body has to support. Comrades marathon runners may decrease this energy expenditure (and protect their ankle joints) by virtue of their training in preparation for this ultra marathon and thereby keeping their weight down. 


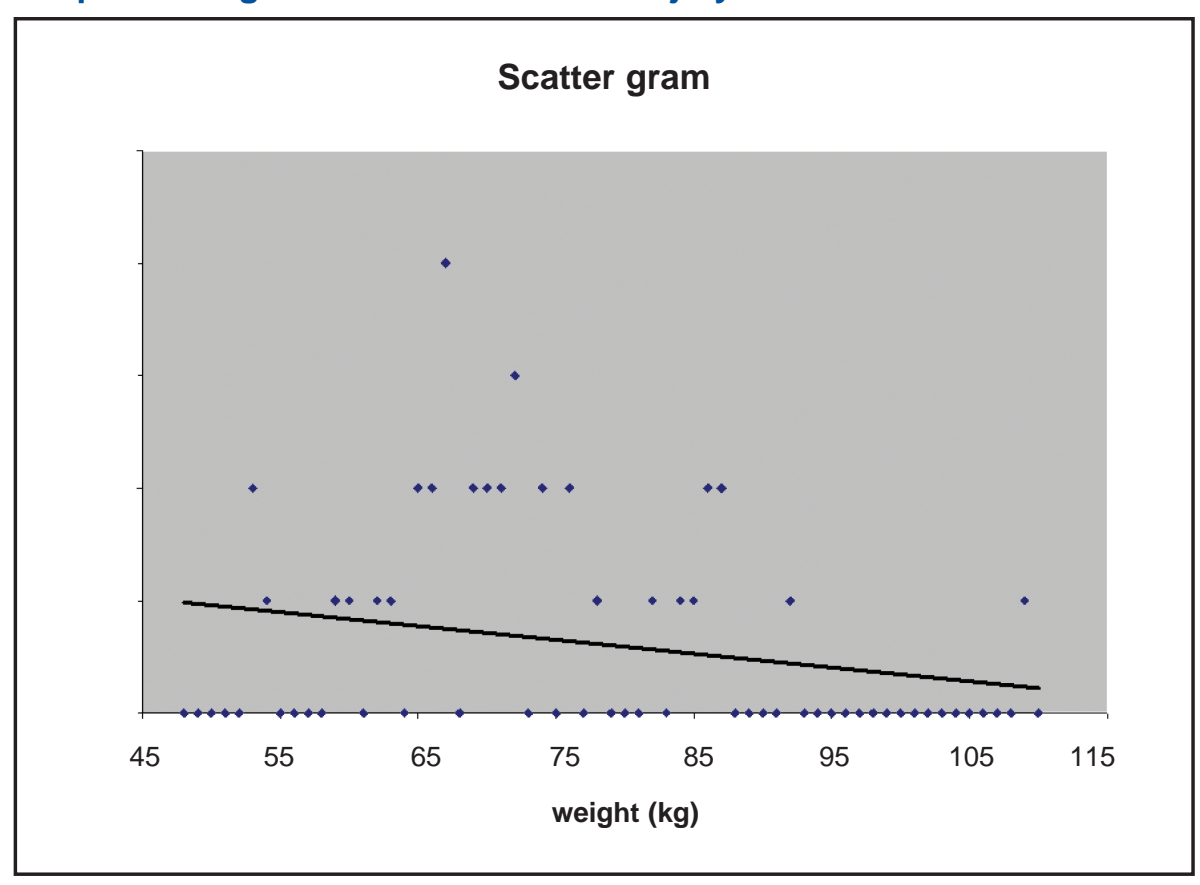

Table 2: Key to Graph 2

\begin{tabular}{|l|l|}
\hline Correlation coefficient & -0.24 \\
$\mathrm{R}^{2}$ & 0.059 \\
Power of correlation (\%) & 5.93 \\
\hline
\end{tabular}

Graph 3: Height versus Incidence of Injury.

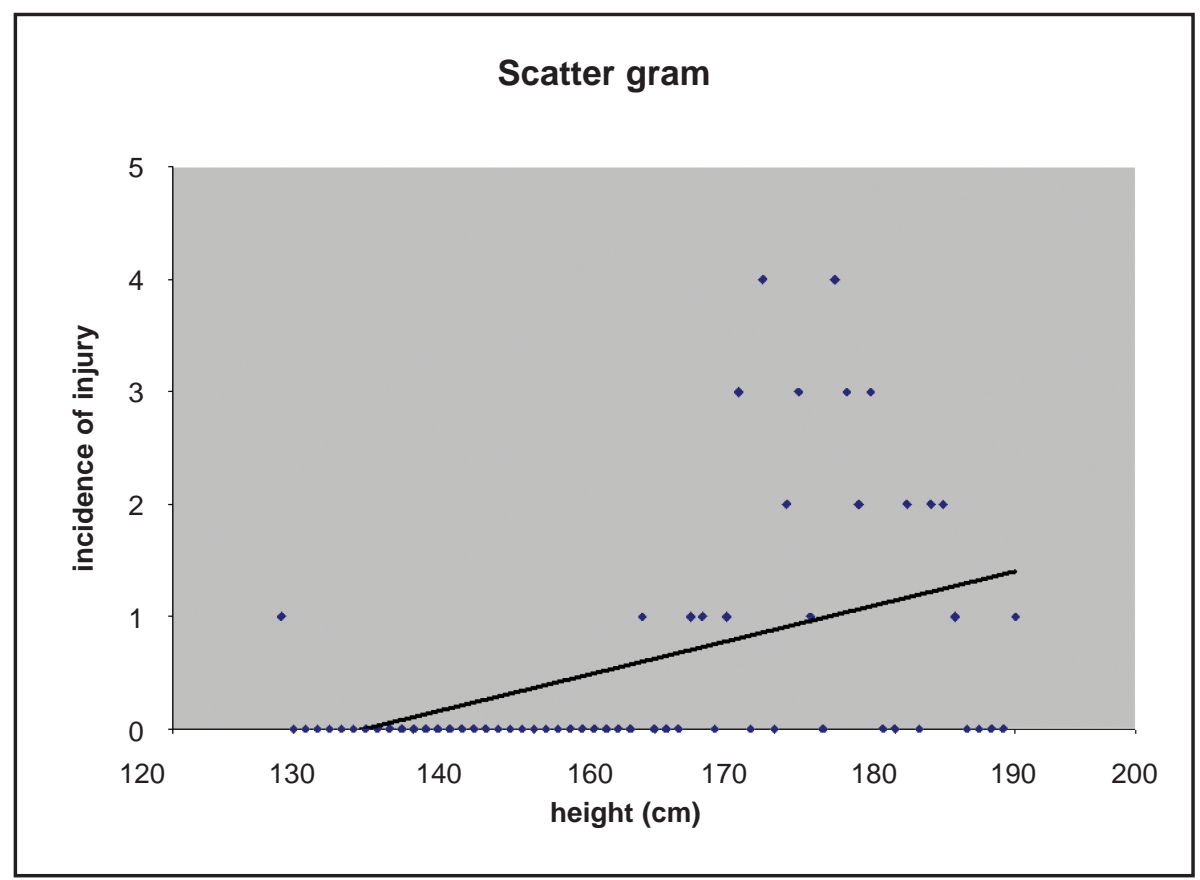

Table 3: Key to Graph 3

\begin{tabular}{|l|l|}
\hline Correlation coefficient & 0.428 \\
$\mathrm{R}^{2}$ & 0.184 \\
Power of correlation (\%) & 18.37 \\
\hline
\end{tabular}

\subsection{Height}

When examining height as a risk factor, it was speculated that the incidence of injury would increase as the subjects' height increased. Our results show that there was a positive correlation coefficient of 0.428 . This figure however indicates that there is a weak relationship between the variables, and it is not statistically significant. The power of the correlation was only $18.3 \%$, which is low, and does not allow for linear regression which would enable us to accurately determine at which height runners would be at the most risk. On average, injured subjects were $1.53 \mathrm{~cm}$ taller that uninjured subjects which is statistically insignificant. These results correspond with those of Beynnon et al (2001) and Sitler et al (1994) whose studies both found that height was not a risk factor for ankle injuries.

\subsection{External variables}

- Mileage - an increase in training mileage would increase the chance of sustaining an injury due to the amount of time spent on the road. Results however showed that on average, injured subjects did less mileage in training for the 2006 Comrades, by $21 \mathrm{~km}$. This decreased mileage could contribute, at least in part, to lateral ankle instability.

- Cross training - may increase the risk if it involves training on moving surfaces or undulating terrain. It may also strengthen the ankle joint if done appropriately. Of the injured athletes only $39.5 \%$ did cross train, whereas $44.7 \%$ of non-injured athletes did some sort of cross training. Although this is a small margin, this difference could contribute to strengthening the ankle to offer some protection against injury.

- Age - the average age of the subjects in this study was 39 years, with the average age for injured athletes being 40 and uninjured athletes 38 years. This does not indicate any affect on the overall results.

- Anatomy of the foot - Past research has led us to believe that deviation from normal arches (either high or low arches) would increase the risk of injury. Results illustrates that $73.7 \%$ 
of injured subjects had normal arched feet, whereas only $67.1 \%$ of uninjured subjects and normal arched feet. This may be explained by the advancement in shoe and orthotic technology, as well as ultra marathon runners' awareness of potential for injury and for the injury itself.

- Previous ankle injury - this is the most published of all the risk factors for ankle injury. However for the purpose of this study, any lateral ankle injury, whether it was a recurrent or first time ankle injury was considered to be a positive for previous ankle injury. Thus previous ankle injury was not considered to negatively affect the out come of the study.

\subsection{Limitations}

- Sample size - The sample size was small compared to the number of participants in the Comrades Marathon.

- Subjects were accessed while awaiting a complimentary massage, thus subjects were limited to those attending the Physiotherapy stand.

- Time constraints - Data collection was carried out during specific times by one researcher, so only those subjects attending at these times were given the opportunity to participate.

- Due to the nature of the sport of ultra distance running, certain body types and body compositions are more compatible. This would decrease the range of height and especially weight of the subjects.

- Questionnaire responses are assumed to be honest, truthful and accurate.

\section{CONCLUSION}

This study, set out to establish whether height, weight and limb dominance were in fact risk factors for lateral ankle injuries. The study revealed that there was no relationship between weight and the incidence of injury. The relationship between both height and limb dominance and the incidence of injury was also insignificant. By proving the null hypothesis, it was established that neither height, weight or limb dominance were significant risk factors for lateral ankle injuries in this study. This is in accordance with other similar studies, which illustrates that these three characteristics are consistently not risk factors. This could assist healthcare professionals in the screening process to identify runners who are at risk of ankle injury.

\section{RECOMMENDATIONS}

Since this study has proven that the characteristics of height, weight and limb dominance are not independent risk factors for lateral ankle injury, it begs the question, 'what is?' The most recent studies however, including that of Tyler et al (2005), invites us to look at the intrinsic factors of height and weight, not independently, but in different forms, such as lean muscle mass, body fat content, body mass index (BMI), mass moment of inertia and Quetelet index. New studies need to look into ways to standardize methods used to accurately measure these variables.

\section{REFERENCES}

Beynnon BD, Renström PA, Alosa DM, Baumhauer JF, Vacek PM. Ankle ligament injury risk factors: a prospective study of college athletes. J Orthop Res. 2001; 19: 213-220.

Beynnon BD, Murphy DF, Alosa DM. Predictive Factors for Lateral Ankle Sprains: A Literature Review. J Athl Train. 2002 Oct-Dec; 37(4): 376-380.

Brukner P. Khan K. Clinical Sports Medicine 3rd Edition. 2006 Mixed Media Product, Sydney.

Comrades Marathon Association 2008. www.comrades.com (accessed 23 July 2008).

Crawly P, France E. Biomechanics of the lateral ligaments of the ankle: An evaluation of the effects of axial load and single plane motions on ligament strain patterns. Foot and Ankle Int, 12 (2): 92-99, 1991.

Ekstrand J, Gillquist J. Soccer injuries and their mechanisms: A prospective study. Med Sci Sports Exerc. 1983; 15: 267-270.

Gage J, Deluca P, Renshaw T. Gait analysis: principles and applications. J Bone \& Joint Surg (Am) 77-A (10) : 1607-23, Oct 1995.

Giza E, Fuller C, Junge A, Dvorak J. Mechanisms of foot and ankle injuries in soccer. Am J Sports Med. 2003; 31: 550-554.

Hreljac A. Impact and overuse injuries in runners. May 2004. Medicine and Science in Sports and Exercise; 36 (5): 845-849
Ishikawa M, Pakaslahti J, Komi PV. Medial gastrocnemius muscle behaviour during human running and walking. Gait and Posture 2007; 25 (3): 380-84

Leardini A, O'Connor JJ, Catani F, Giannini $\mathrm{S}$. The role of the passive structures in the mobility and stability of the human ankle joint: A literature review. Foot \& Ankle Int. 2000; 21: 602-613.

Li L,j van den Bogert ECH, Caldwell GE, van Emmerik A, Hamill J. Coordination patterns of walking and running at similar speed and stride frequency. Human Movement Science. Feb 1999; 18 (1): 67-85

McKay GD, Goldie PA, Payne WR. Ankle injuries in basketball: Injury rate and risk factors. Br J Sports Med 2001; 35: 103-8.

Milgrom C, Shlamkovitch N, Finestone A, Eldad A, Laor A, Danon Y, Lavie O, Wosk J, Simkin A. Risk factors for lateral ankle sprain: a prospective study among military recruits. Foot Ankle:1991; 12: 26-30

Murphy DF, Connolly D, Beynnon BD. Risk factors for lower extremity injury: a review of the literature. Br. J. Sports Med $2003 ; 37 ; 13-29$

Sitler MR, Ryan J, Wheeler B. The efficacy of a semi-rigid ankle stabilizer to reduce acute ankle injuries in basketball: a randomized clinical study at West Point. Am J Sports Med.1994; 22: 454-461.

Surve I, Schwellnus MP, Noakes T, Lombard C. A fivefold reduction in the incidence of recurrent ankle sprains in soccer players using the sportstirrup orthosis. Am J Sports Med. 1994; 22: 601-606.

Tyler TF, McHugh MP, Mirabella MR, Mullaney ML, Nicholas SJ. Risk factors for non-contact ankle sprains in high school football players: The role of previous ankle sprains and body mass index. Am J Sports Med 2005

Van Gent RN, Stein D, van Middelkoop M, van Os AG, Bierma-Zienstra SMA, Koes BW. Incidence and determinants of lower extremity running injuries in long distance runners: A systematic review. British J Sports Med 2007; 41: 469-480

Van Middelkoop M, Kolkman J, van Ochten J, Bierman-Zienstra SM, Koes BW. Risk factors for lower extremity injuries among male marathon runners. Clin J Sport Med 2007; 17 (1): 25-30.

Watson AW. Ankle sprains in players of the field-games Gaelic football and hurling. J Sports Med Phys Fitness.1999; 39: 66-70. 